\title{
Is the Undergraduate Forensic Medicine Teaching Adequate to Produce an Expert Medical Witness?
}

\author{
Amal Nishantha Vadysinghe ${ }^{* 1} \otimes\left(\right.$ iD) $\quad$ Deepthi Edusooriya ${ }^{1}$, Subodhi P Dayaratne ${ }^{1}$, Nayana MK \\ Manoratne $^{2}$, Yasitha Abeysekara², Punsisi WADPM Nissanka² \\ ${ }^{\mathbf{1}}$ Department of Forensic Medicine, Faculty of Medicine, University of Peradeniya, Sri Lanka. \\ ${ }^{2}$ Postgraduate institute of Medicine, University of Colombo, Sri Lanka.
}

\section{Introduction}

In Sri Lanka, medico-legal work is carried out by specialist and non-specialist government medical practitioners. Therefore, the Forensic Medicine program assumes an important position in the undergraduate medical curriculum. The Objective Structured Practical Examination (OSPE) conducted in the third or fourth year in the undergraduate curriculum of most medical faculties in Sri Lanka is designed to assess practical aspects of key areas in forensic medicine. This study evaluates scores of the OSPE in undergraduates.

\section{Methods}

A selected sample of 515 answer scripts of fourth-year medical students in five consecutive batches from 2009-2013, were evaluated by two authors and the scores analysed.

\section{Results}

The mean scores for injury description were 51.6\%, 58\% and 59.5\% for burns, fractures and basic injuries, respectively. Fifty-seven percent of students demonstrated competence with regard to MLEF and MLR documentation with marked weakness in stating the cause of death. Thirty-eight percent obtained less than $50 \%$ for questions related to identification and interpretation of postmortem changes, artefacts, injuries and pathological changes. Thirty-three percent scored less than 50\% marks in the medico-legal interpretation of skeletal remains. In the study, more than $50 \%$ of students scored more than $80 \%$ marks in toxicology. Students obtained an average score of $68 \%$ and $51 \%$ respectively in the identification of dissecting instruments and dissection techniques.

\section{Conclusions}

The need to strengthen the undergraduate forensic medicine curriculum with close supervision by specialists and training of medical officers prior to engaging in medico-legal work is recommended to prevent gross errors in medicolegal practice.

Keywords: OSPE, Forensic medicine, Medico-legal opinion, Undergraduate curriculum

Copyright: @ 2017 with the Medico-legal Journal of Sri Lanka.

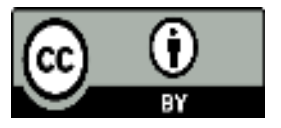

This is an open access article distributed under the terms of the Creative Commons Attribution License, CC BY 4.0 which permits unrestricted use, distribution and reproduction in any medium, provided the original author and source are credited.

Funding: None, Competing interests: None

Received: 25 November 2017

Accepted revised version: 20 March 2018

Published: 01 April 2018

https://orcid.org/0000-0002-1994-7830

*Corresponding author: Vadysinghe AN, Tel: +94718037908, E mail address: amal_vadysinghe@yahoo.com $\triangle$ Cite this article as: Vadysinghe AN, Edusooriya D, Dayaratne SP, Manoratne NMK, Abeysekara Y, Nissanka WAPDPM. Is the Undergraduate Forensic Medicine Teaching Adequate to Produce an Expert Medical Witness?. Medico-Legal Journal of Sri Lanka, 2017;5(2):5-10

DOI: http://doi.org/10.4038/mljsl.v5i2.7357 


\section{Introduction}

Forensic Medicine is a medical speciality, where medical knowledge is used in the process of ensuring justice. The Sri Lankan medico-legal system and practice is based on the British model. Sri Lanka is one of the few countries where a significant proportion of the medico-legal work is carried out by non-specialist medical practitioners. Even though some training is provided to them in instances where they assume posts such as Medical officer-medico legal, many perform medico-legal duties with only the competencies acquired during medical school, as under graduates. Therefore, the Forensic Medicine program assumes an important position in the undergraduate medical curriculum. This emphasizes the responsibility vested upon the undergraduate teachers to ensure that students acquire the expected level of competency in carrying out basic medico-legal work independently. [1-4]

The undergraduate Forensic Medicine teaching program consists of classroom teaching as well as a clinical appointment. While the content theory knowledge is evaluated via written examinations the practical skills are assessed by an Objective Structured Practical Examination (OSPE).

Use of the OSPE as a method of evaluating practical skills has been documented. ${ }^{\left[{ }^{[-9]}\right.}$ The use of this method in the Sri Lankan context is further emphasized by the fact that this method is cost and time effective and enables the examiner to evaluate a wide range of practical skills.

In this background, the objective of this study was to evaluate the performance of fourth-year medical students at the OSPE in Forensic Medicine.

\section{Materials and methods}

The OSPE examination in Forensic Medicine was formulated by academic and extended academic staff of the Department of Forensic medicine based on a blueprint to include areas such as injury description, Medico-legal documentation in Medico-legal examination form(MLEF), Medico-legal Report (MLR), post-mortem report (PMR) with stating of the cause of death (COD), identification of postmortem changes and artefacts, identification and interpretation of injuries and pathological changes, medico-legal interpretation of skeletal remains, identification of instruments and dissection techniques.
The examination was conducted for each clinical group on the last day of the clinical appointment in Forensic medicine of one-month duration. A selected sample of 515answerscripts of fourth-year medical students in five consecutive batches from 2009-2013, were evaluated by two authors and the scores analyzed.

\section{Results}

1. Questions on medico-legal aspects of injuries The average marks of injury description for basic injuries, fractures and burns were above $50 \%$ with $59.5 \%(n=293)$ for basic injuries, $58 \%(n=298)$ for fractures with a slight weakness for the description of burns (51.6\%, n=267)(Fig. 1)

Figure 1: Mean scores for questions related to injury description

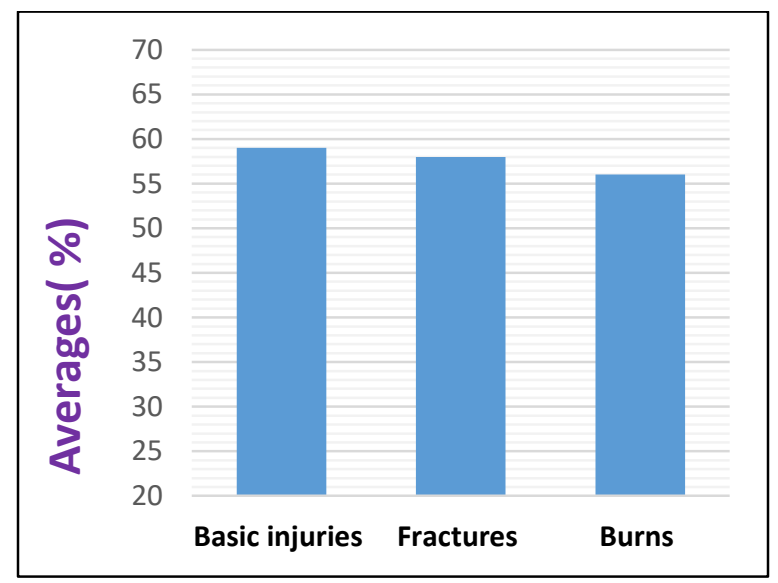

2. Questions on medico-legal documentationEvaluation of Questions relating to completing the MLEF, MLR and stating the COD was done. The students scored an average of $63 \%(n=324)$ and $58 \%$ $(\mathrm{n}=299)$ for MLEF and MLR documentation respectively. Only $40 \%(n=206)$ of students stated the COD correctly (Fig. 2). 
Figure 2: Mean scores for questions related to Medico legal documentation

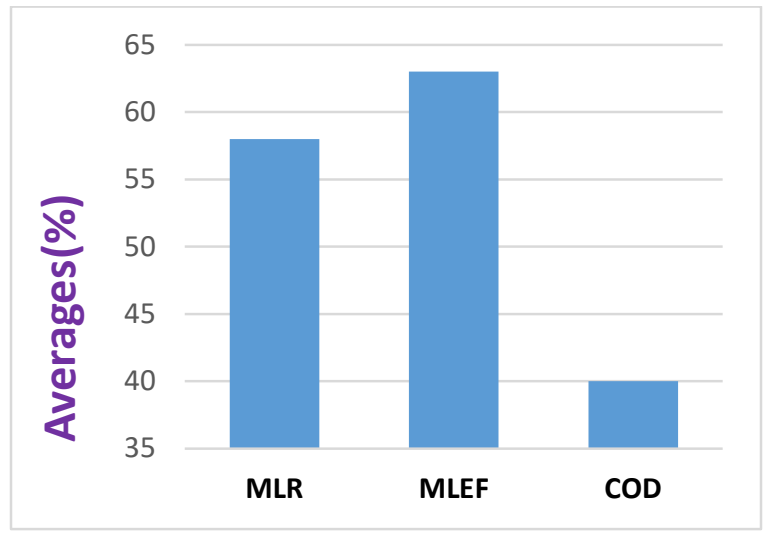

3. Questions on identification of postmortem changes, injuries and pathology- Analysis of scores of the OSPE questions on identification of PM changes, artefacts and in identification and interpretation of injuries and pathological changes indicated that $38 \%(n=196)$ of students performed poorly (obtained less than 50\%) in related questions (Fig 3).

Figure 3: Mean scores for questions related to identification of PM changes, artefacts, identification and interpretation of injuries and pathological changes

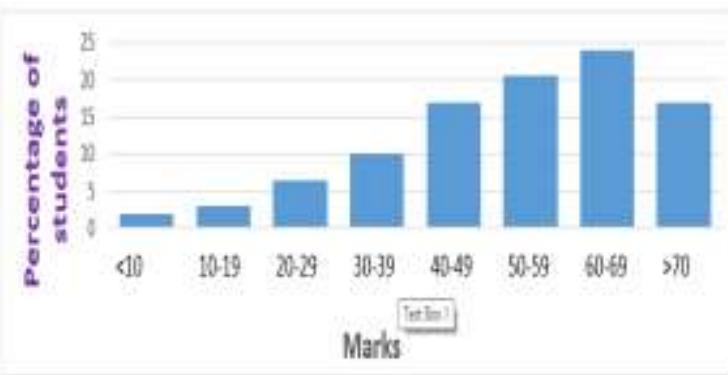

4. Questions on examination of skeletal remainsAnalysis of scores of questions on general identification and medico-legal interpretation of skeletal productions indicated that $33.5 \%(n=175)$ of students scored less than 50 marks (Fig 4).
Figure 4: Mean scores for questions related to medico-legal interpretation of skeletal remains

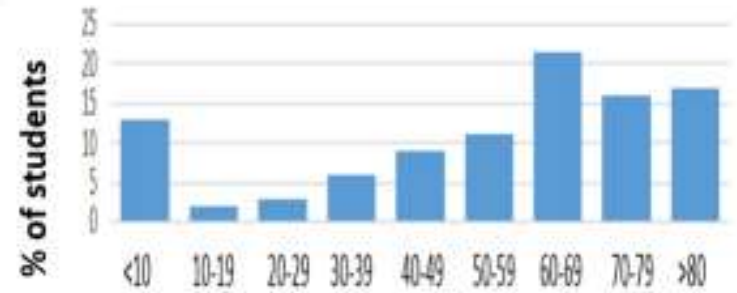

Marks

5. Questions on forensic toxicology and handling of specimens - When scores related to the handling of specimens (identification of appropriate specimens for investigation, preservation, storage and transportation) and toxicology were analysed the average mark was $54.7 \%$ with $67 \%(n=345)$ of students scoring more than 50 marks (Fig. 5).

Figure 5: Mean scores for questions related to Identification of appropriate specimens for investigation, preservation, storage and transportation and knowledge of toxicology

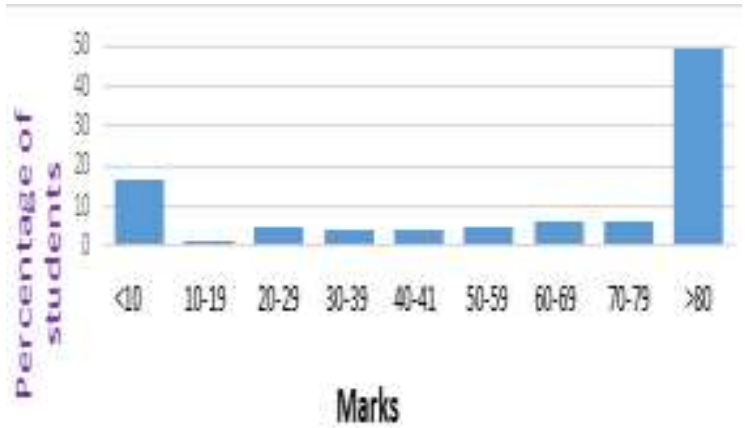

6. Questions on dissection techniques and instruments- In this analysis, the scores to questions related to the identification of instruments used in dissection, clinical examination and investigation and related knowledge were analysed. Students obtained an average mark of $68 \%$ in identification of instruments used in forensic practice with an SD of 15.95. However, they scored an average of 51\% with $\mathrm{SD}$ of 34 in questions related to dissection techniques (Table1). 
Table 1: Scores for questions related to the identification of instruments used in forensic practice and dissection technique

\begin{tabular}{lccccc}
\hline \hline Item & $\begin{array}{c}\text { No. } \\
\text { of } \\
\text { Stud } \\
\text { ents }\end{array}$ & $\begin{array}{c}\text { Aver } \\
\text { age } \\
(\%)\end{array}$ & $\begin{array}{c}\text { Min } \\
(\%)\end{array}$ & $\begin{array}{c}\text { Max } \\
(\%)\end{array}$ & SD \\
\hline $\begin{array}{l}\text { Instrument } \\
\text { Identification }\end{array}$ & 515 & 68 & 25 & 100 & 15.95 \\
$\begin{array}{l}\text { Dissection } \\
\text { Techniques }\end{array}$ & 484 & 51 & 0 & 100 & 34 \\
\hline \hline
\end{tabular}

\section{Discussion}

The Forensic medicine component of the undergraduate medical curriculum has been designed to enable medical graduates to perform basic medicolegal work in the capacity of intern medical officers or as post-intern medical officers. The OSPE in Forensic Medicine is used as a yardstick in determining whether students acquired adequate training in the clinical and pathological aspects of Forensic Medicine to function as expert medical witnesses to courts. Those who do not obtain the required pass mark (>50\%) are required to repeat the clinical appointment in Forensic Medicine.

Wyatte emphasizes the importance of being knowledgeable about identification, interpretation and documentation of injuries in medical practice. ${ }^{[10]}$ It is especially important for junior doctors as they most often function in the capacity of first contact doctors and need to possess the ability to identify, interpret and document findings on bed head ticket before any intervention. The study revealed that the students had acquired a reasonable degree of competence in describing injuries for medico-legal purposes with a slight weakness for the description of burns.

Stark highlights the importance of correct documentation in forensic practice .Furthermore, in Sri Lanka completion of the MLEF and MLR is important for medical officers who have examined victims for medico-legal purposes. [11] This study revealed a high level of competence among students regarding MLEF and MLR documentation, which indicates the adequacy of the clinical program.

On the other hand, stating of COD is another important aspect of death investigation and it is vested upon the medical officer to provide the correct cause of death as required for medico-legal purposes. This is crucial for ensuring justice in homicides, for compensation, insurance purposes, pensions, national statistics or disposal of properties etc. ${ }^{[12,13]}$ This study revealed a marked weakness among students in stating the COD which indicates the necessity to strengthen this area in the curriculum.

Interpretation of postmortem changes, postmortem artefacts are an important entity in formulating medico-legal opinions such as time since death and cause of death in death investigation. ${ }^{[14-18]}$ This study revealed that a significant proportion of students performed poorly in questions related to the identification of postmortem changes, artefacts and in identification and interpretation of injuries and pathological changes

This study revealed that a significant proportion of students performed poorly in the medico-legal interpretation of skeletal remains. This process is purely an academic exercise within the Forensic medicine undergraduate appointment as interpretation of skeletal remains is not directly under the purview of a first contact, non-specialist medical officer. It may be reasonable to withdraw this component from the evaluation.

Specimen collection for investigation is an important aspect in forensic crime investigation. ${ }^{[19-21]}$ It will provide scientific evidence which can be corroborated by the other expert opinions. The Medical officer handles the biological specimens and his contribution towards forensic examination is invaluable. This includes identification of appropriate specimen for investigation, preservation, storage and transportation and knowledge of toxicology. This study revealed that the knowledge of identification of appropriate specimen, preservation, storage, transportation and knowledge of toxicology was marginal in the students. This indicates that a medical officer with undergraduate knowledge may not be competent in handling such cases.

The post-mortem represents the examination of the body after death in order to determine the cause and manner of death as well as to evaluate any disease or injury that may be present. ${ }^{[2]}$ There may be substantial discrepancies between clinical diagnoses and findings at autopsy. The autopsy may be used as a tool for quality management to analyse diagnostic discrepancies. ${ }^{[23]}$ Therefore it is important to use correct dissection techniques and instruments during post-mortem procedures. This study demonstrated a high level of competency in the identification of instruments used in forensic practice. However, they were less competent in dissection techniques. 


\section{Conclusion}

Students showed satisfactory level of competency with regard to completing the MLEF and MLR, forensic toxicology and identification of instruments used in forensic practice. However, a significant proportion of students lacked competence in identification/ interpretation of postmortem artefacts, burns and pathological changes. Improvement is also required in areas of skeletal analysis, stating the COD and theory related to dissection techniques.
It is recommended that the undergraduate curriculum be strengthened with close supervision of medical students by forensic specialists. Furthermore, it would be beneficial to commence a special training for Medical Officers prior to engaging in medico-legal practice especially in places where specialists in forensic medicine are not available.

\section{References}

1. Kumara C. Introduction - Faculty of Medical Sciences, University of Sri Jayewardenepura [Internet]. Medical.sjp.ac.lk. 2017 [cited 16 November 2017]. Available from:

http://medical.sjp.ac.lk/index.php/forensic-medicine-introduction

2. Medical website [Internet]. Med.pdn.ac.lk. 2017 [cited 16 November 2017]. Available from: http://med.pdn.ac.lk/departments/forensic/academic.html

3. Kodikara S. Practice of clinical forensic medicine in Sri Lanka: Does it need a new era?. Legal Medicine. 2012; 14(4):167-71.

DOI: http://doi.10.1016/j.legalmed.2012.02.003

4. Balachandra AT, Vadysinhe AN, William AL. Practice of forensic medicine and .pathology in Sri Lanka Arch Pathol Lab Med .2011;135(2):187-90

DOI: http://doi.10.1043/2008-0397-CCR.1.

5. Edussuriya D, Marambe K, Abeyasinghe N, Jayawickramarajah P. Competencies expected from a medical officer in Performing medico legal duties: the results of a Delphi study conducted among judicial medical officers in Sri Lanka. Sri Lanka Journal of Forensic Medicine, Science \& Law. 2013;3(2):6-14.

DOI: http://dx.doi.org/10.4038/sljfmsl.v3i2.5435

6. Menezes R, Nayak V, Binu V, Kanchan T, Rao P, Baral P. Objective structured practical examination (OSPE) in Forensic Medicine: Students’ point of view. Journal of Forensic and Legal Medicine. 2011; 18(8):347-9.

DOI: http://doi.10.1016/j.jflm.2011.06.011

7. Harden R, Cairncross R. Assessment of practical skills: The objective structured practical examination (OSPE). Studies in Higher Education. 1980;5(2):187-96.

DOI: http://doi.org/10.1080/03075078012331377216

8. Nayar U, Malik S, Bijlani R. Objective structured practical examination: a new concept in assessment of laboratory exercises in preclinical sciences. Medical Education. 1986;20(3):204-9.

DOI: http://doi.org/10.1111/j.1365-2923.1986.tb01169.x

9. Malik S, Manchanda S, Deepak K, Sunderam K. The attitudes of medical students to the objective structured practical examination. Medical Education.1988; 22(1):40-6.

DOI: http://doi.org/10.1111/j.1365-2923.1988.tb00407.x

10. Wyatt J, Payne-James J, Norfolk G, Squires T. Oxford handbook of forensic medicine. Oxford: Oxford University Press; 2015.

11. Stark M. A physician's guide to clinical forensic medicine. Totowa, N.J.: Humana Press; 2000. 
12. Danilova I, Shkolnikov V, Jdanov D, Meslé F, Vallin J. Identifying potential differences in cause-of-death coding practices across Russian regions. Population Health Metrics. 2016;14(8):12-19.

DOI: http://doi.org/10.1186/s12963-016-0078-0

13. Vadysinghe A, Abeysekara A, Gunasena M, Ratnayake R. Life insurance policy: is it an indication for inquest?. Sri Lanka Journal of Forensic Medicine, Science \& Law. 2012;3(1)23-24.

DOI: http://doi.org/10.4038/sljfmsl.v3i1.4950

14. Prahlow J, Byard R. Atlas of forensic pathology. New York: Springer; 2012.

15. Kanchan T, Acharya J. Pellets or maggots? - A case report on artefacts in forensic medicine. Egyptian Journal of Forensic Sciences. 2015;5 (4):180-2.

DOI: https://doi.org/10.1016/j.ejfs.2014.11.001

16. Tsokos M, Matschke J, Gehl A, Koops E, Püschel K. Skin and soft tissue artefacts due to postmortem damage caused by rodents. Forensic Science International. 1999;104 (1):47-57.

DOI: https://doi.org/10.1016/S0379-0738(99)00098-5

17. Haglund W. Postmortem Artefacts of Cats and Rats. The American Journal of Forensic Medicine and Pathology. 1991;12 (4):355.

18. Mirza F, Makhdoom P. Importance of Correct Interpretation of Postmortem Artefacts in Medico-legal Autopsies. Journal of Pakistan Medical Association.1998;49-50.

19. Robertson J. Trace evidence - disappearing fast?. Australian Journal of Forensic Sciences. 2010;42 (2):79-80. DOI: https://doi.org/10.1080/00450611003769758

20. Lee HC, Pagliaro EM. Forensic Evidence and Crime Scene Investigation. J Forensic Investigation. 2013;1(2):25.

21. Vallejo CA, Edsicker D. Crime Scene Investigation and Physical Evidence Manual. town and press. 2001.

22. Costache M, Lazaroiu, AM, Contolenco A, Costache D, George S, Sajin M, Patrascu OM. Clinical or Postmortem? The Importance of the Autopsy; a Retrospective Study. Mædica. 2014; 9(3):261-5

23. Shojania K, Burton E, McDonald K, Goldman L. Changes in Rates of Autopsy-Detected Diagnostic Errors Over Time. JAMA.2003; 289(21):2849-55. DOI:

DOI: http://doi.10.1001/jama.289.21.2849 